East African Medical Journal Vol. 87 No. 6 June 2010

SHORT TERM CLINICAL OUTCOME OF CHILDREN WITH ROTAVIRUS INFECTION AT KENYATTA NATIONAL HOSPITAL, NAIROBI

B. O. Osano, MBChB, MMed (Paed.) Paediatrician, P. O. Box 4888-00506, Nairobi, Kenya, R. W. Kamenwa, MBChB, MMed (Paed), Fellowship (Paed. Gastro), Lecturer, Department of Paediatrics and Child Health, Aga Khan University Hospital, Nairobi, P.O. Box 30270 - 00100, Nairobi, Kenya, D. Wamalwa, MBChB, MMed (Paed), MPH, Senior Lecturer, Department of Paediatrics and Child Health and J. K. Wang'ombe, BA, MA, PhD (Health Econ), Professor, College of Health Sciences, Department of Community Health, University of Nairobi, P.O. Box 19676-00202, Nairobi, Kenya

Request for reprints to: Dr. B. O. Osano, P. O. Box 4888-00506, Nairobi, Kenya

\title{
SHORT TERM CLINICAL OUTCOME OF CHILDREN WITH ROTAVIRUS INFECTION AT KENYATTA NATIONAL HOSPITAL, NAIROBI
}

\author{
B. O. OSANO, R. W. KAMENWA, D. WAMALWA and J. K. WANG'OMBE
}

\begin{abstract}
Background: Rotavirus infection is the single most common cause of acute gastroenteritis in children under five years of age. Rotavirus gastroenteritis has a high morbidity and mortality in children in Kenya.

Objectives: To determine the short term clinical outcome for children admitted to Kenyatta National Hospital with rotavirus gastroenteritis and the correlates of poor outcome.

Design: Short longitudinal survey.

Setting: Kenyatta National Hospital from February to May 2008.

Subjects: Five hundred children were screened using a rapid antigen detection kit and ELISA.

Results: Of the 191 children who tested positive for rotavirus in stool; 172 children were recruited into the study. Eighty eight per cent of the patients were discharged within one week, $8.1 \%$ stayed for more than seven days while $4.1 \%$ died. Children who had co-morbidities such as malnutrition, rickets and pneumonia had worse outcomes. Conclusion: Rotavirus gastroenteritis has a long hospital stay and a high mortality. Children in shock on admission and those with co-morbid conditions should get priority for they have a poor outcome.
\end{abstract}

\section{INTRODUCTION}

Globally gastroenteritis is a leading cause of morbidity and mortality in children under five years of age (1). Diarrhoea is a major cause of morbidity among children in Kenya (2). Rotavirus is the single most common cause of acute gastroenteritis (AGE) in children and it is often more severe than the gastroenteritis caused by other enteropathogens. The peak infection with rotavirus is at 3-24 months of age $(1,3)$. Rotavirus acute gastroenteritis (RVG) is characterised by fever, vomiting and diarrhoea. The stools are pale, watery or loose with a characteristic milky odour. The diarrhoea lasts 3-8 days but it has been documented to last as long as 22 days. Fever and vomiting are most prominent in the initial few days $(4,5)$. Less well recognised is the association of rotavirus-induced central nervous system dysfunction, which has been associated with seizure, encephalopathy and death (6). Early complimentary feeding has been found to be an important risk factor for rotavirus gastroenteritis (5). Management is supportive with fluid replacement, anti-pyretics for those who have a fever and specific management of co-morbid conditions.

Rotaviruscauses 111 millionepisodes of diarrhoea requiring home care alone, 25 million clinic visits, two million hospitalisations and 352,000-873,000 deaths (median 520,000 deaths) in children under five years per year. By the age of five years, one in five of the world's children will require a clinic visit, 1 in 65 will require hospitalisation and approximately 1 in 293 will die. More than $80 \%$ of these deaths occur in subSaharan Africa and Asia $(7,8)$. Rotavirus is detected in $13-73 \%$ of children hospitalised for AGE. Diversity of strains and the deaths are more frequent in subSaharan Africa. The higher mortality in developing countries is probably due to poor access to healthcare facilities, high prevalence of HIV / AIDS and higher levels of malnutrition (1,7-9). In Canada, the mean duration of hospitalisation for rotavirus was $2.4 \pm 1.7$ days but was significantly longer in children with an underlying medical condition (10). The mean of length of hospital stay was $4.4 \pm 3.3$ days in Taiwan (11). 
In Kenyatta National Hospital, rotavirus infection admission case fatality rate was $11.6 \%$ in a prior study (12). There is evidence to suggest that malnourished children have a more severe disease and co-infection with adenovirus may prolong duration of diarrhoea to 10-14 days (4,13-14). The objective of our study was to determine short term clinical outcomes of children admitted to $\mathrm{KNH}$ with rotavirus gastroenteritis. We also sought to determine correlates of poor outcomes due to acute rotavirus infection in children at $\mathrm{KNH}$. Potential correlates include age and co-morbidities such as HIV, severe malnutrition and adenovirus co-infection.

\section{MATERIALS AND METHODS}

This was a short longitudinal survey in Kenyatta National Hospital from February to May 2008. The study was carried out among children aged 0 to 35 months admitted to paediatric wards with acute gastroenteritis. Their stool was tested for RV antigen by rapid antigen detection test and confirmed by ELISA within 48 hours of admission. Sequential sampling of patients who met the inclusion criteria was done. Demographic data was obtained and entered into a pre-structured questionnaire. Comorbid conditions were established from patient's clinical records and physical examination. Poor outcome was taken as death and/or a hospital stay from admission to discharge of more than seven days. Ethical approval was obtained from the KNH Ethics and Research Committee. Informed written consent was obtained from the caretaker.

\section{RESULTS}

Five hundred children with acute gastroenteritis were tested for rotavirus and adenovirus. The prevalence of rotavirus and adenovirus was $38.2 \%$ and $2.2 \%$, respectively. The prevalence of co-infection with both rotavirus and adenovirus was $0.4 \%$. Table 1 shows the socio-demographic characteristics of the children who were recruited into the study. There were slightly more males than females, ratio of 1.4:1. The mean age was 8.7 months with range ( 1 month -35 months). One third of the patients were weaned within the first month of life and $8 \%$ were weaned at six months. The patients came from all geographical areas of Nairobi and a few of its suburbs. The patients were from low and middle socio-economic status.
Table 1

Socio-demographic characteristics of the patients $(n=172)$

\begin{tabular}{cc}
\hline Characteristic & $\begin{array}{c}\text { Frequency (\%) } \\
\text { or Mean (SD) }\end{array}$ \\
\hline $\begin{array}{c}\text { Sex (Male) } \\
\text { Age (months) }\end{array}$ & $99(58)$ \\
Mean age (SD) & $8.7(5)$ \\
Age categories (\%) & \\
$\leq 6$ & $58(34)$ \\
$7-12$ & $86(50)$ \\
$13-18$ & $23(13)$ \\
$18+$ & $5(3)$
\end{tabular}

Age at complimentary feeding (Months)

Mean complimentary feeding age (SD)

Complimentary feeding age categories (\%)

$\begin{array}{lr}0-2 & 106(62) \\ 3-4 & 43(25) \\ 5-6 & 21(12) \\ >6 & 2(1) \\ \text { Relationship with caretaker } & 155(90) \\ \text { Mother } & \\ \text { Father } & 170(99) \\ \text { Grandmother } & 1(0.5) \\ \end{array}$

Age of caretaker (years)

Mean age of caretaker (SD) 25.6 (4.9)

Caretaker age categories $(\%)$

$\begin{array}{lr}\leq 20 & 16 \\ 21-30 & 127 \\ 31-40 & 26 \\ 40+ & 3\end{array}$

Education of caretaker

None

Primary

Secondary

Post Secondary

Occupation of caretaker

No formal employment

/ Housewife

Business

Casual labourer

Salaried employment

Other

1 (1) 
Table 2 summarises selected clinical and laboratory characteristics of the patients. All patients had diarrhoea which was an inclusion criterion. The other symptoms were not present in all the patients. However, all the patients presented with two or more complaints. Nineteen $(11 \%)$ patients had all the four symptoms of fever, vomiting, diarrhoea and convulsions. Only two patients acknowledged having taken herbal or traditional medications. There were some patients who had more than one co-morbid illness. Rapid HIV test was positive in twelve (7\%) of the patients. The patients confirmed to have HIV were three $(1.7 \%)$, they had other underlying/comorbid illnesses with CD $4<10 \%$.

The overall mean hospital stay in the hospital from admission was 4.2 days to discharge and 5.9 days to going home. The number of children who died was seven $(4.1 \%$, 95\% CI 1.2-6.9). Of the children who died, the mean stay and SD in the ward before death was $4 \pm 3.2$ days. Table 3 gives mean (SD) of key outcomes of the patients seen. Those with a good outcome (alive and hospital stay $>7$ days) were $151(87.8 \%)$ while poor outcome (death or hospital stay $>7$ days) were $21(12.2 \%)$. Most children with good outcomes were discharged within three days. The number of children with long hospital stay (more than 7 days) was 14 (8.1 $\%)$. There were $77(44.8 \%$ ) patients who stayed for extra days after discharge. Children with co-morbidities were more likely to have poor outcomes.

At the point of going home, 84 patients $(48.8 \%)$ had completely recovered, $77(44.8 \%)$ were partially recovered while four $(2.3 \%)$ absconded (left the hospital secretly before settling bills and without being officially released). Partial recovery group consisted of the children who were discharged on oral rehydration fluids after successful rehydration although diarrhoea had not completely stopped.

Table 4 shows the association between patient characteristics and outcomes. Severe wasting (Z-score weight-for-age $<-3$ ), patients with co-morbidities and shock on admission were the significant predictors of poor outcome. Patients aged six months or less showed a trend of having poor outcomes.

HIV and malnutrition, co-morbid conditions that have been postulated to have poor outcomes, were analysed separately. The rest were analysed together, however, those with high numbers, pneumonia and rickets, were additionally analysed independently to see individual contribution to outcome. Twelve children had more than one co-morbid condition. Having more than one co-morbidity in one patient was not significantly associated with poor outcome.

Table 5 shows the multivariate analysis predictors of poor outcomes. Shock was the strongest predictor of poor outcome. A young age of six months or less was a significant predictor of poor outcome on multivariate analysis.

Table 2

Selected clinical and laboratory characteristics $(n=172)$

Characteristic Frequency (\%) or Mean (SD)

Duration of illness

before admission $3.85(2)$

Fever

Duration in days

Vomiting

Episodes per day

Duration in days

Convulsions

Number of episodes per day

Duration in days

Diarrhoea

Episodes per day

Duration in days

Other household members

with diarrhoea

Had sought care elsewhere prior

to coming to $\mathrm{KNH}$

Referred to $\mathrm{KNH}$

Any co-morbidity

Co-morbidities other than

malnutrition, HIV and adenovirus

Rapid test positive for HIV-1

Adenovirus positive

Weight for age Z-score

$$
\begin{aligned}
& <-3 \\
& -3 \text { to- } 2
\end{aligned}
$$

$>-2$

Height for age Z-score

$<-3$

-3 to-2

$>-2$

Weight for height Z-score

$$
\begin{aligned}
& <-3 \\
& -3 \text { to }-2
\end{aligned}
$$

$>-2$ 
Table 3

Key outcomes: length of hospital stay and mortality

\begin{tabular}{lllll}
\hline & $\begin{array}{l}\text { All } \\
\text { patients } \\
(\mathrm{n}=172)\end{array}$ & $\begin{array}{l}\text { Any co- } \\
\text { morbidity } \\
(\mathrm{n}=59)\end{array}$ & $\begin{array}{l}\text { No co- } \\
\text { morbidity } \\
(\mathrm{n}=113)\end{array}$ & P-value \\
\hline $\begin{array}{l}\text { Duration of stay } \\
\text { To discharge/death }\end{array}$ & $4.2(5.3)$ & $6.7(8.2)$ & $2.9(1.8)$ & $<0.001$ \\
$\quad \begin{array}{l}\text { To going home } \\
\text { Extra days after discharge }\end{array}$ & $5.9(7.5)$ & $8.8(11.1)$ & $4.4(4.0)$ & $<0.001$ \\
$\begin{array}{l}\text { Poor outcome } \\
\quad \begin{array}{l}\text { Death - Frequency (\%) } \\
\text { Length of stay }>7 \text { days }\end{array}\end{array}$ & $7(3.6)$ & $2.1(4.2)$ & $1.5(3.3)$ & 0.302 \\
& $14(19)$ & $5(8.5)$ & $2(1.8)$ & 0.038 \\
\hline
\end{tabular}

Table 4

Univariate analysis of outcome and patient's characteristics $(n=172)$

\begin{tabular}{|c|c|c|c|c|}
\hline \multicolumn{5}{|c|}{ Outcome } \\
\hline Factor & $\begin{array}{l}\text { Poor }(\%) \\
(\mathrm{n}=21)\end{array}$ & $\begin{array}{l}\text { Good }(\%) \\
(\mathrm{n}=151)\end{array}$ & OR $95 \% \mathrm{CI}$ & P-value \\
\hline HIV exposed & $3(14.3)$ & $9(6.0)$ & $2.6(0.5-12.1)$ & 0.160 \\
\hline Z-score Weight for Age $<-3$ & $4(19.0)$ & $9(6.0)$ & $3.7(0.9-15.3)$ & 0.03 \\
\hline Z-score Weight for Height $<-3$ & $2(9.5)$ & $9(6.0)$ & $1.9(0.3-10.7)$ & 0.53 \\
\hline Z-score Height for Age $<-3$ & $2(9.5)$ & $4(2.6)$ & $3.9(0.5-27.3)$ & 0.11 \\
\hline Co-morbid other than above* & $10(47.6)$ & $30(19.9)$ & $3.7(1.3-0.4)$ & $<0.01$ \\
\hline Rickets & $4(19.0)$ & $11(7.3)$ & $3.0(0.7-1.9)$ & 0.07 \\
\hline Pneumonia & $3(14.3)$ & $8(5.3)$ & $3.0(0.6-14.1)$ & 0.12 \\
\hline Sex (male) & $11(52.4)$ & $88(58.3)$ & $0.8(0.3-2.2)$ & 0.69 \\
\hline Age ( $\leq 6$ months) & $11(52.4)$ & $47(31.1)$ & $2.4(0.9-6.7)$ & 0.05 \\
\hline Not breastfeeding & $3(14.3)$ & $14(9.3)$ & $1.6(0.3-7.0)$ & 0.47 \\
\hline $\begin{array}{l}\text { Duration of illness before } \\
\text { admission ( } \geq 4 \text { days) }\end{array}$ & $11(52.4)$ & $63(41.7)$ & $1.5(0.6-4.2)$ & 0.36 \\
\hline Referred & $12(57.1)$ & $64(42.4)$ & $1.8(0.7-5.0)$ & 0.20 \\
\hline No prior care received & $5(23.8)$ & $52(34.4)$ & $0.6(0.2-1.9)$ & 0.33 \\
\hline $\begin{array}{l}\text { Severity of dehydration } \\
\text { Shock }\end{array}$ & $10(47.6)$ & $14(9.3)$ & $8.9(2.9-27.9)$ & 0.01 \\
\hline \multicolumn{5}{|c|}{$\begin{array}{l}\text { *o-morbidities includes all others like pneumonia and rickets but excludes malnutrition and HIV } \\
\text { exposure }\end{array}$} \\
\hline Factor & & ODDs & & P-value \\
\hline Weight for age Z-Score (Z-WA) & & 1.09 & & 0.003 \\
\hline Age ( $\leq 6$ months) & & 1.26 & & 0.016 \\
\hline Co-morbid (other than HIV and & EM) & 1.26 & & 0.010 \\
\hline Shock (on admission) & & 1.07 & & $<0.001$ \\
\hline
\end{tabular}




\section{DISCUSSION}

The rotavirus prevalence of $38.2 \%$ among the children admitted with acute gastroenteritis is within the range noted in most hospital studies $(1,5,10)$. The RVG prevalence in this study is less than the $59 \%$ as was reported by Gatinu (12). This difference could be attributed to the seasonality of rotavirus, our study was conducted in a different peak season from Gatinu's study. More than $80 \%$ of the children with rotavirus were below 12 months of age. However, in this study, the fraction of those under six months was high at $34 \%$ compared to other studies where it was about $10 \%$ or less $(5,10)$. Less than $10 \%$ of the children were exclusively breastfed forsix months. Early introduction of complimentary feeds may predispose the infants to acquiring RVG early (5). The children came from all geographical areas of Nairobi, although they were mainly from low socio-economic status. KNH mainly serves patients from low economic status, hence the high numbers from such background. The adenovirus prevalence of $2.2 \%$ in this study is comparable to $2.5 \%$ reported by Kow Tong et al. (11) and $2 \%$ by Basu et al. (15) among infants. In this study, the co-infection of rotavirus and adenovirus was in less than $2 \%$ of the study patients. This is much lower than the $8.3 \%$ noted by Forbes et al. (16). The study by Forbes et al. (16) had an upper age limit of 16 years while the studies by Kow Tong et al. (11) and Basu et al (17) had an upper age limit of five years. Our study had an upper age limit of 36 months.

The patients admitted had the expected common symptoms of rotavirus; $97.7 \%$ had vomiting while 91.9\% had fever. These were also the common symptoms in a study in Brazil by Carneiro et al. (5), while in the Canada study by Ford-Jones et al., 97\% reported vomiting and $89 \%$ reported fever (10). There were few convulsion episodes and a short duration of convulsions before admission. This could be because the caretakers consider convulsions a more serious symptom and seek medical care quickly as compared to diarrhoea and vomiting. The common co-morbid conditions were rickets, pneumonia and bronchospasms. Rickets was diagnosed as the single leading co-morbidity in about $9 \%$ of the study patients. All children (100\%) received some form of fluids, either intravenous or oral, to restore and/or replace losses, whereas only $94 \%$ received fluids in the study by Ford-Jones et al (10). More than $75 \%$ of the patients received antibiotics even though less than 35\% were documented to have co-morbidities. Some patients may have had a high respiratory rate secondary to dehydration or metabolic acidosis which may have led to a diagnosis and treatment for pneumonia. It is noteworthy that high respiratory rate is in keeping with diagnosis of pneumonia according to the Integrated Management of Childhood Illness (IMCI) guidelines.
The rotavirus infection admission case fatality rate was $4.1 \%$ in this study. This is much lower than the $11.6 \%$ reported by Gatinu et al at (12) but higher than rates reported in more developed countries (9). The case fatality rate from rotavirus gastroenteritis may have decreased from the time Gatinu et al. (12) did study as there has been a lot of staff training on emergency care of children presenting in theemergency room in KNH. This training mighthaveimproved careof patients presenting in $\mathrm{KNH}$. The mean duration of hospitalisation before death in this study was four days (SD 3.2). This is longer than mean duration of hospitalisation before death of 1.8 days reported by Gatinu et al. (12). This could also bedue toimproved emergency care. The improved care of very sick children may have led to keeping the very sick children alive longer before their death. Before the trainings, the very sick children may have died soon afteradmission hence the shorter duration of stay before death in the earlier study.

The mean of length of stay to discharge for all patients was 4.2 (SD 5.3). It is comparable to $4.4 \pm 3.3$ days reported by Kow Tong et al. (11) and 5.2 days reported by Nokes et al. (17). In our study, majority $(68 \%)$ of the children with a good outcome were discharged within three days. Poor outcomes were more likely to occur in those with co-morbidities compared to those who did not have any underlying/ co-morbid illness. The mean $( \pm S D)$ of length of stay to discharge was $2.9( \pm 1.8)$ for those with no co-morbid illness, comparable to $2.4 \pm 1.7$ seen in children with no underlying illness in Canada (10) while it was $6.7( \pm 8.2)$ for those with co-morbidities. The patients with co-morbidities stayed significantly longer in the hospital before being discharged and also before going home. This could be among other things due to time taken to investigate and treat comorbid diseases or that they took longer to recover due to reduced immunity as may be the case in malnourished and HIV infected children $(13,14,18)$. Children with severe wasting had a worse outcome compared to those without. Worse outcome for those with underlying illnesses has also been documented in other studies $(10,13,14)$ and postulated in Malawi (18). The worse outcome may not be a result of the rotavirus effects alone but also due to the multiple effects of the other illnesses, such as a poor immune system from malnutrition and a natural progression of the co-morbidities. Other underlying conditions such as stunting, rickets or pneumonia on their own did not influence outcomes. The individual illnesses when analysed separately may not have had an effect on outcome as their numbers were too small, hence limited power, to bring out any statistical differences. Shock was the single most important predictor of poor outcome on univariate and multivariate analysis. This could reflect the significant physiological changes that may have resulted from severe dehydration which may be more difficult to reverse than severe 
dehydration without shock. The duration the patient had been in shock may be important but the study had not sought this out. This highlights the need for urgentemergency intervention in patients presenting in shock and with co-morbidities. Age of six months or less was an independent predictor of poor outcome on multivariate analysis. Getting RVG at thisearly age may be an indicator of low passive immunity from mothers or due to effects of early complimentary feeding. Early complimentary feeding has also been shown to be a risk factor for acquiring RVG (5). Protection in neonatal period is conferred via transplacental maternal antibodies and by antibodies and other factors such as lactoadherin transferred through breastfeeding. Lactoadherin in human milk is believed to interfere with rotavirus replication (19). In this study exclusive breastfeeding rate was very low. Early mixed feeding may have reduced the protective effects of exclusive breastfeeding.

Rotavirus gastroenteritis has a high morbidity and mortality in terms of long hospital stay and high mortality rate for a preventable illness. The children with co-morbidities and those in shock at admission had a poor outcome. All children with acute gastroenteritis should be triaged upon arrival in hospital to identify those in shock and those with co-morbid conditions for priority treatment for they have a poor outcome. Health education to the general public on danger signs in gastroenteritis and when to go to seek medical help before children go into shock may reduce the poor outcome associated with it.

\section{ACKNOWLEDGEMENTS}

GlaxoSmithKline (Kenya) for provision of the rotavirus and adenovirus test kits. Katholischer Akademischer Auslander-Dienst (Catholic Academic Exchange Service) - KAAD for financing the other research costs. The caretakers and their children who participated in this study and the research assistants A. F. Mwadime, C. Mukuha and N. Kiniu for their time and hard work.

\section{REFERENCES}

1. Cunliffe, N. A., Kilgore, P. E., Bresee, J. S., et al. Epidemiology of rotavirus diarrhoea in Africa: a review to assess the need for rotavirus immunization. WHO Bulletin OMS. 1998; 76: 525-537.

2. Central Bureau of Statistics (Kenya), Ministry of Hlth (Kenya) and Macro International. Kenya Demographic and Health Survey 2003. Maternal Child Health. 2004; 9: 123-152.

3. Gatheru, Z., Kobayashi, N., Adachi, N., et al. Characterisation of human rotavirus strains causing gastroenteritis in Kenya. Epidemiol. Infect. 1993; 110: 419-423.

4. Bass, M. D. Rotavirus and other agents of viral gastroenteritis. Nelson's textbook of Paediatrics.
Behrman, R. E., Kliegman, R. M. and Jenson, H. B. Saunders. Philadelphia. 2004; 17(ed): 1081-1083.

5. Carneiro, N. B., Dinis-Santos, K. D., Fagundes, Q. S., et al. Clinical and epidemiological aspects of children hospitalised with severe rotavirus-associated gastroenteritis in Salvador, BA, Brazil. Braz. J. Infect. Dis. 2005; 9: 525-528.

6. Wong, V. and Chung, B. Relationship between five common viruses and febrile seizure in children. Arch. Dis. Child. 2007; 92: 589-593.

7. Miller, M. A. and McCann, L. Policy analysis of the use of hepatitis B, Haemophilus influenzae type B-, streptococcus pneumoniae - conjugate and rotavirus vaccines in national immunization schedules. Hlth. Econ. 2000; 9: 19-35.

8. Parashar, U. D., Hummelman, G. E., Bresee, J. S., et al. Global illness and deaths caused by rotavirus disease in children. Emerg. Infect. Dis. 2003; 9: 565-572.

9. Wessel, F., Nel, G., Snyman, J., et al. The economics of the prevention of rotavirus gastroenteritis: a South African perspective. South Afr. Paed. Review. 2006; 3: 31-38.

10. Ford-Jones, E. L., Wang, E., Petrie, M., et al. Hospitalisation for community-acquired, rotavirusassociated diarrhoea. Arch. Pediatr. Adolesc. Med. 2000; 154: 578-585.

11. Kow-Tong, C., Shiang-Fang, F., Ren-Bin, T., et al. Hospital-based study of the economic burden associated with rotavirus diarrhoea in Taiwan. Vaccine. 2007; 25: 4266-4272.

12. Gatinu, B. W. Prevalence of group A rotavirus and electrolyte profiles in children presenting with acute diarrhoea at KNH. Dissertation for Master of Medicine in Paediatrics and Child Health, University of Nairobi. 2007.

13. Dagan, R., Bar-David, Y., Sarov, B., et al. Rotavirus diarrhea in Jewish and Bedouin children in the Negev region of Israel: epidemiology, clinical aspects and possible role of malnutrition in severity of illness. Pediatr. Infect. Dis. J. 1990; 9: 314-321.

14. Binka, F. N., Anto, F. K., Armah, E. G., et al. Incidence and risk factors of paediatric rotavirus diarrhoea in Northern Ghana. Trop. Med. Intern. Hlth. 2003; 8: 840846

15. Basu, G., Rossouw, J., Sebunya, K., et al. Prevalence of rotavirus, adenovirus and astrovirus infection in young children with gastroenteritis in Gaborone, Botswana. East Afr. Med. J. 2003; 80: 652-655.

16. Forbes, C., Hawkes, M. and Nesbitt, S. Stool viruses among paediatric patients from a Nairobi clinic, Kenya. East Afr. Med. J. 2004; 81: 562-567.

17. Nokes, J. D., Abwao, J., Pamba, A., et al. Incidence and clinical characteristics of Group A Rotavirus infections among children admitted to hospital in Kilifi, Kenya. PLos Medicine. 2008; 5: 1154-1162.

18. Cunliffe, N. A., Gondwe, J. S., Kirkwood, D. C., et al., Effect of concomitant HIV infection on presentation and outcome of rotavirus gastroenteritis in Malawian children. The Lancet. 2001; 358: 550-555.

19. Newburg, D. S., Jerry, A. P. and Guillermo, M. Role of human milk lactoadherin in protection against symptomatic rotavirus infection. The Lancet. 1998; 351: 1160-1164. 